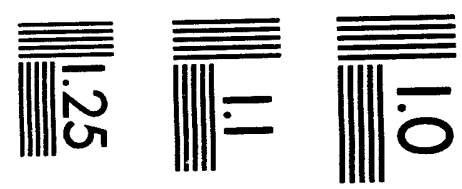

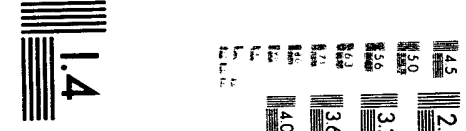

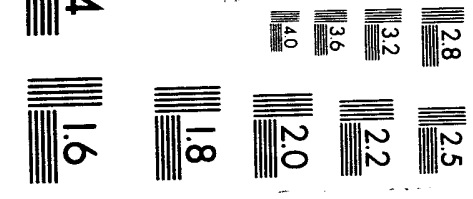



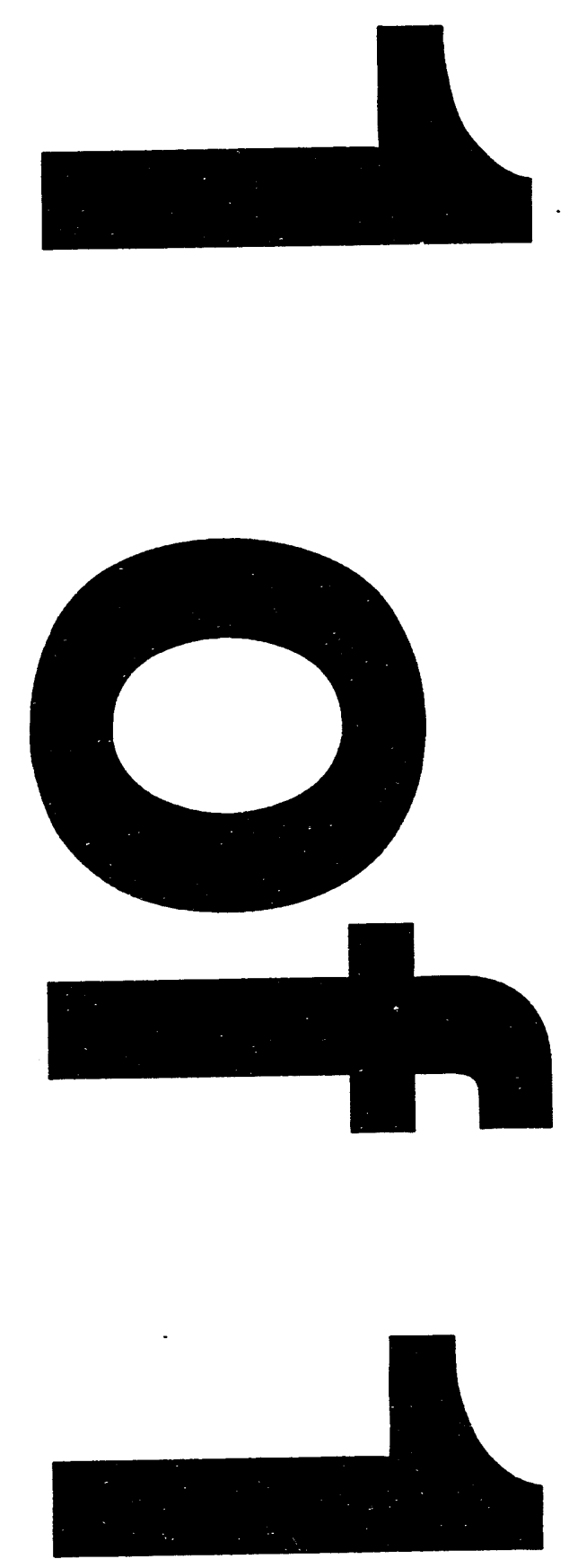

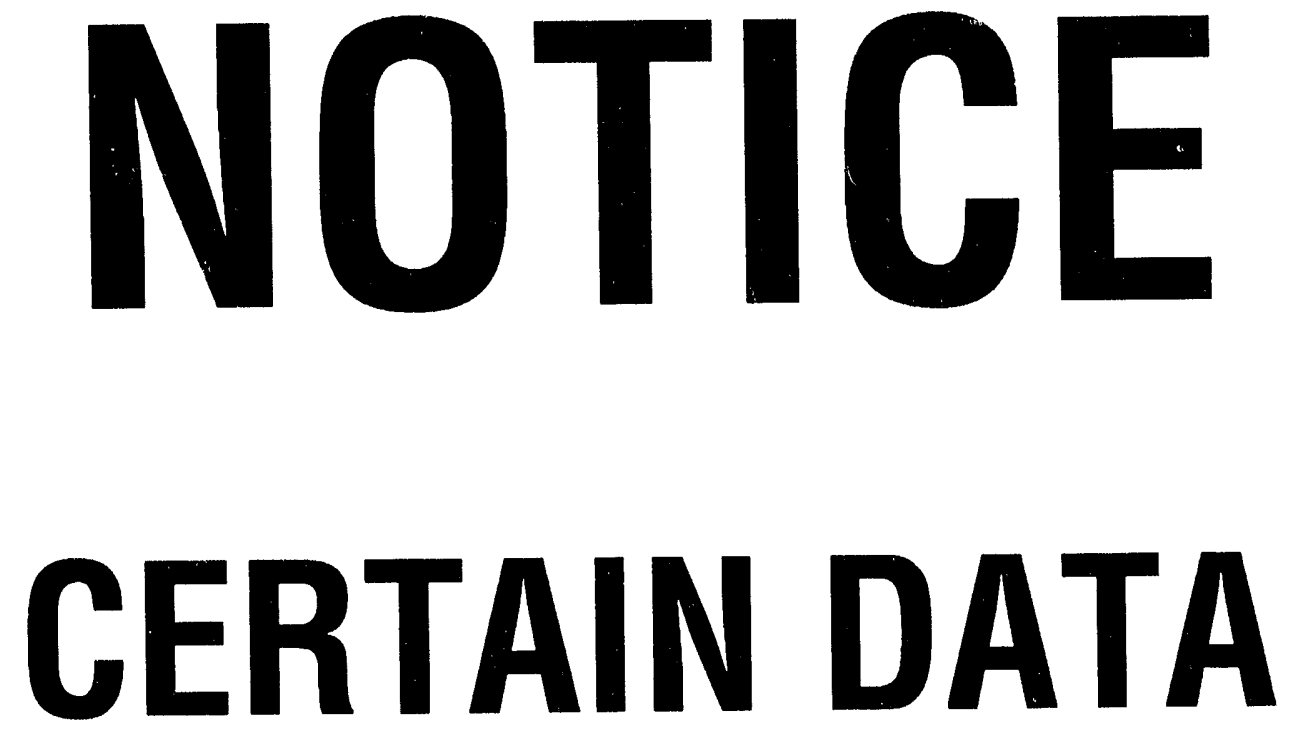

CONTAINED IN THIS
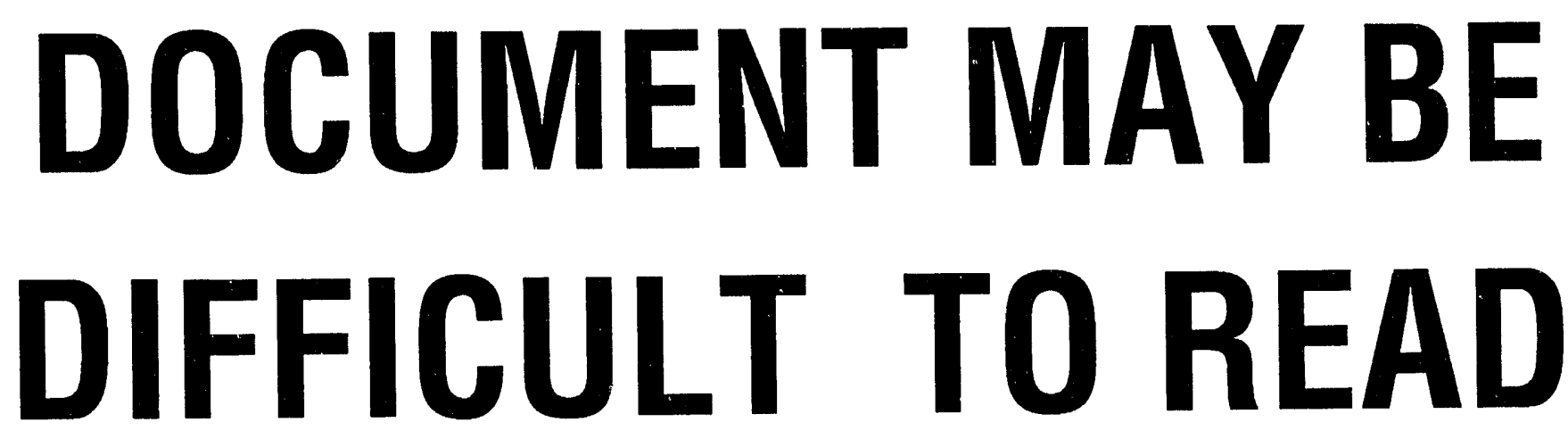

IN MICROFICHE

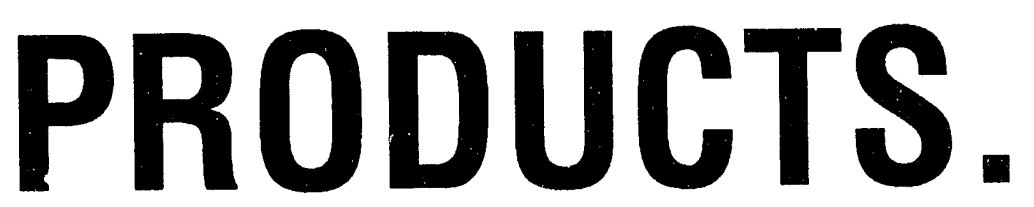




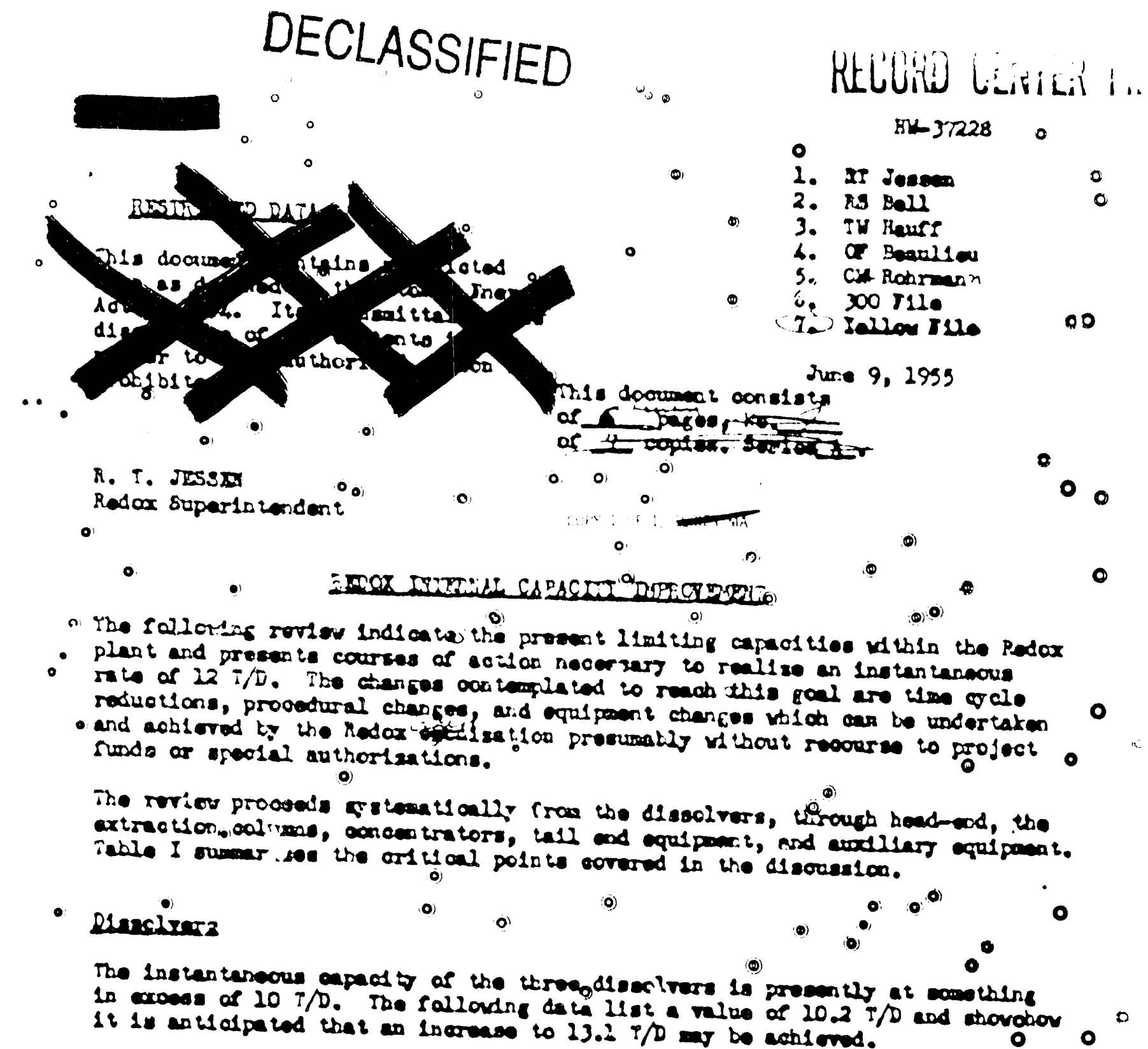

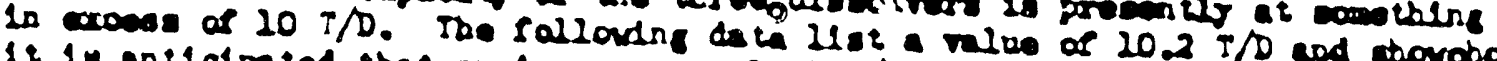

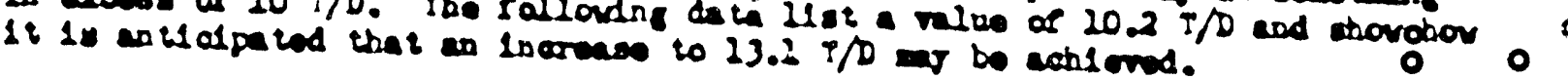

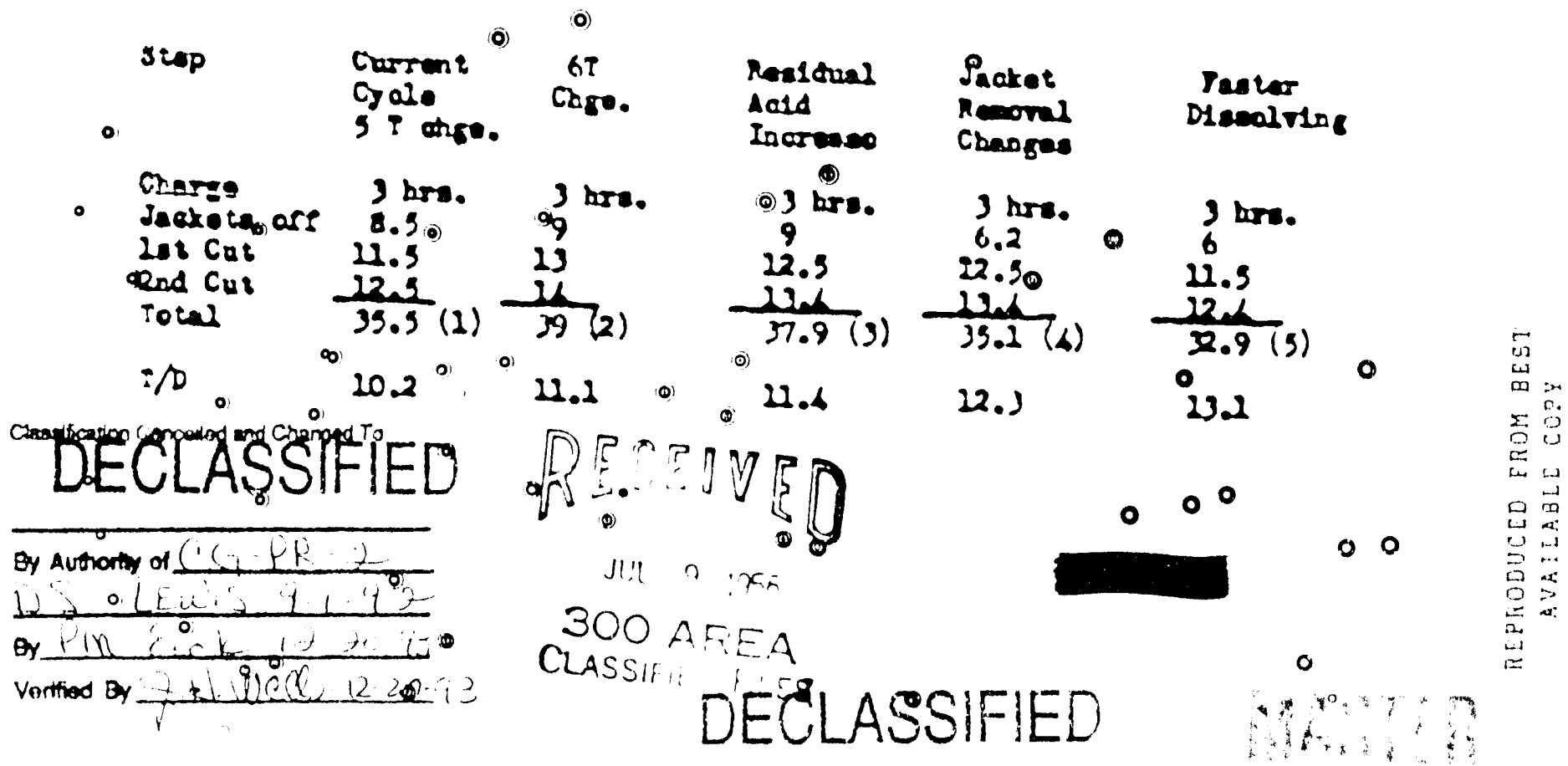




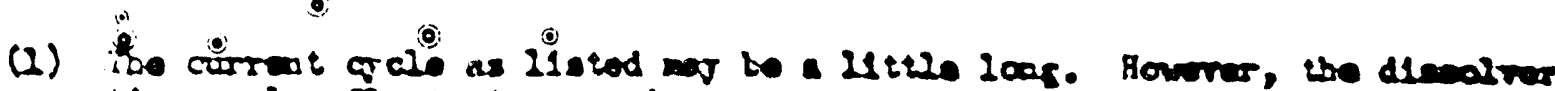

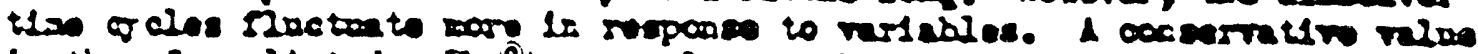

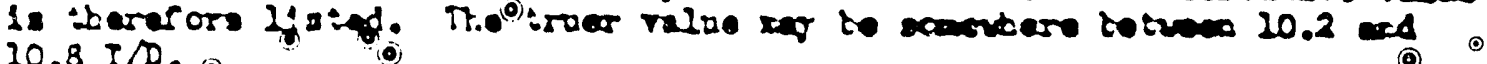
$10.8 \mathrm{I} / \mathrm{D} .0$ (1)

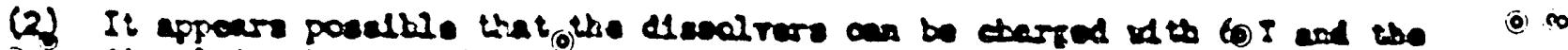

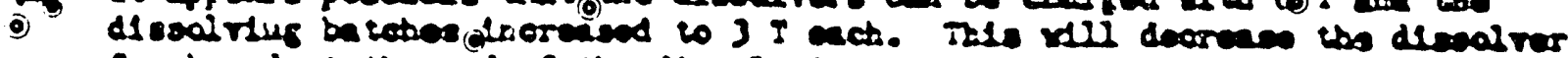

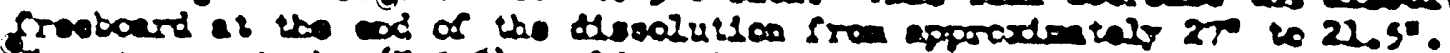

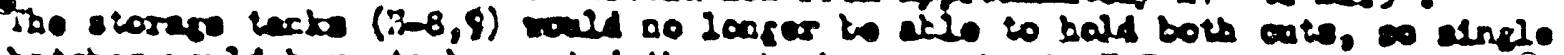

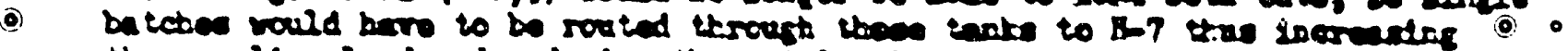

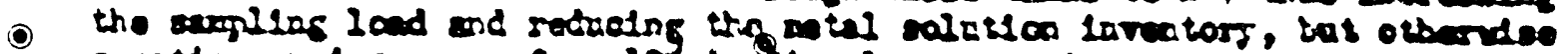

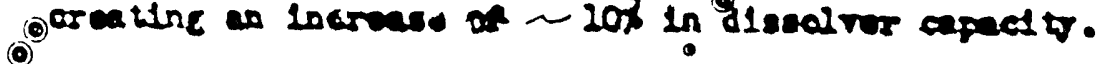

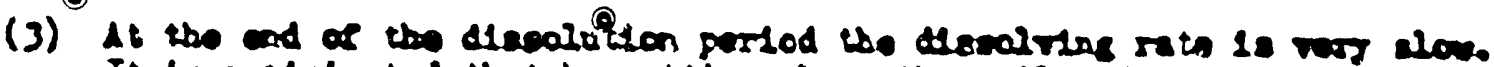

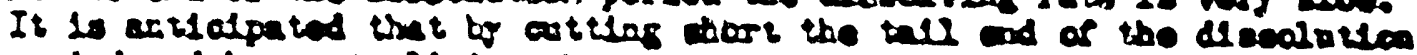

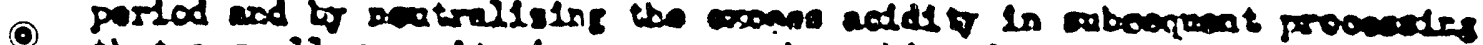

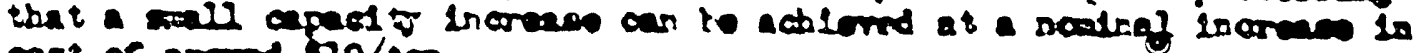
cost of arowad ino/ton.

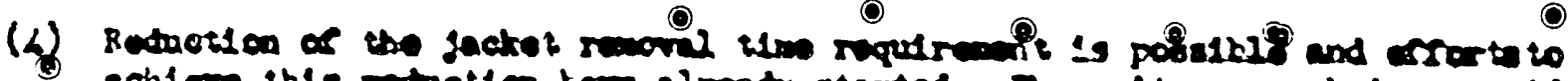

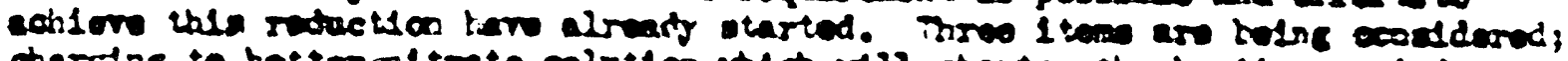

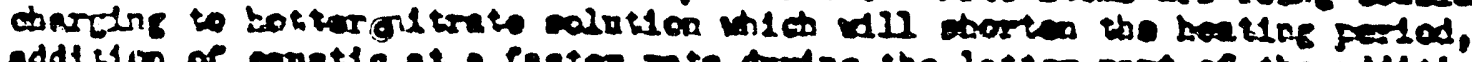

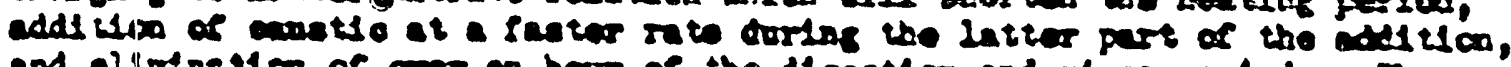

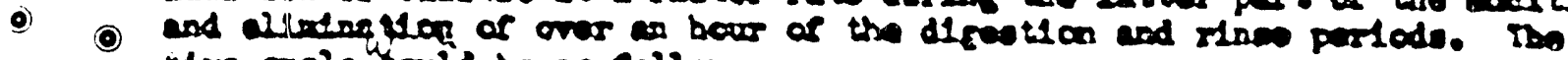
is of ole towint is as soldares

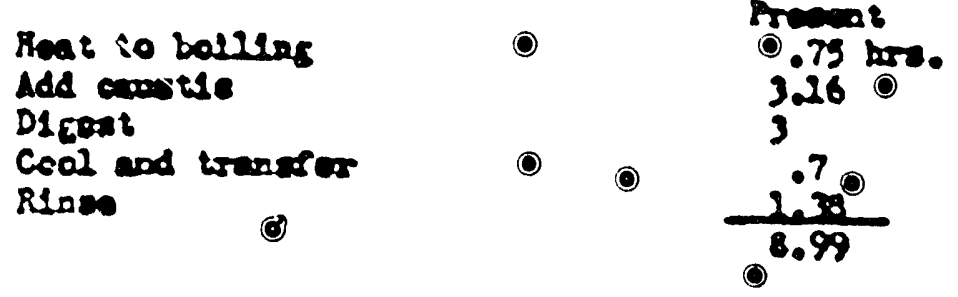

Bropoed
$0 \quad \frac{.50 \text { hre. }}{2.20}$
$0 \quad \frac{0.20}{6.20}$

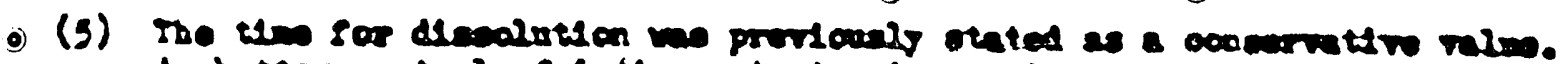

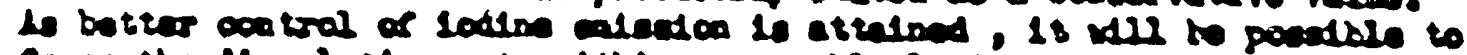

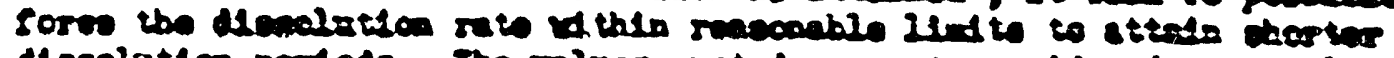

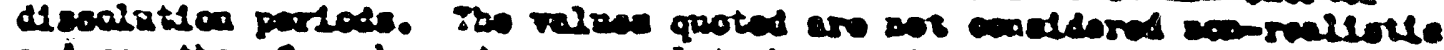

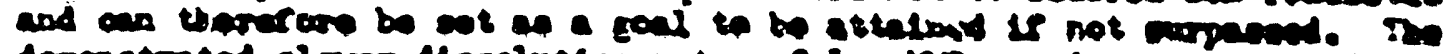

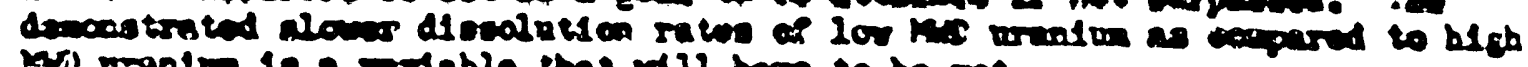

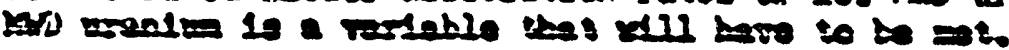

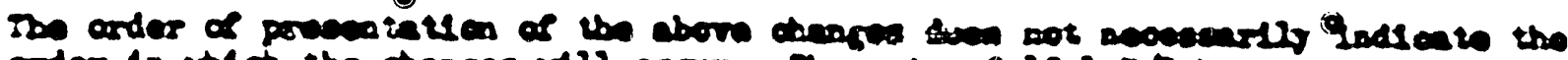

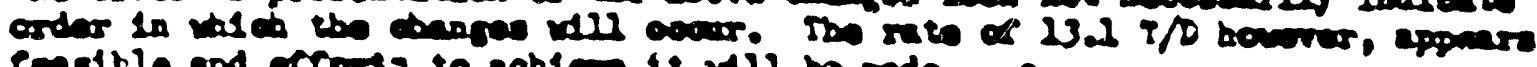

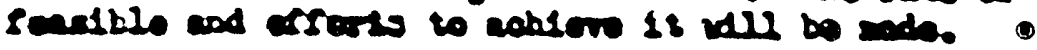

Indist

(ㄷ)

(อ)

0

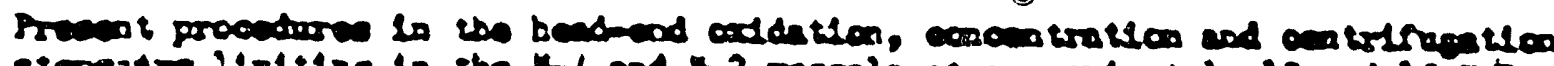

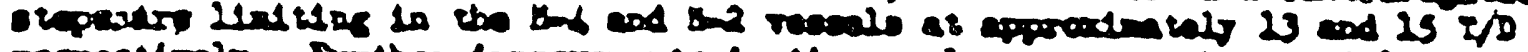

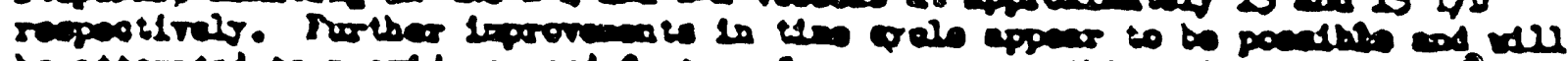

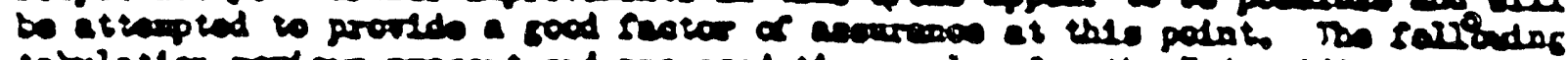

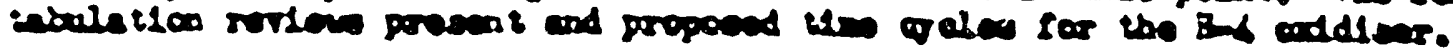

$$
\begin{aligned}
& \text { pionent and propoed the od } \\
& \text { DELLASSIFIER }
\end{aligned}
$$

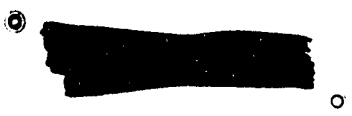




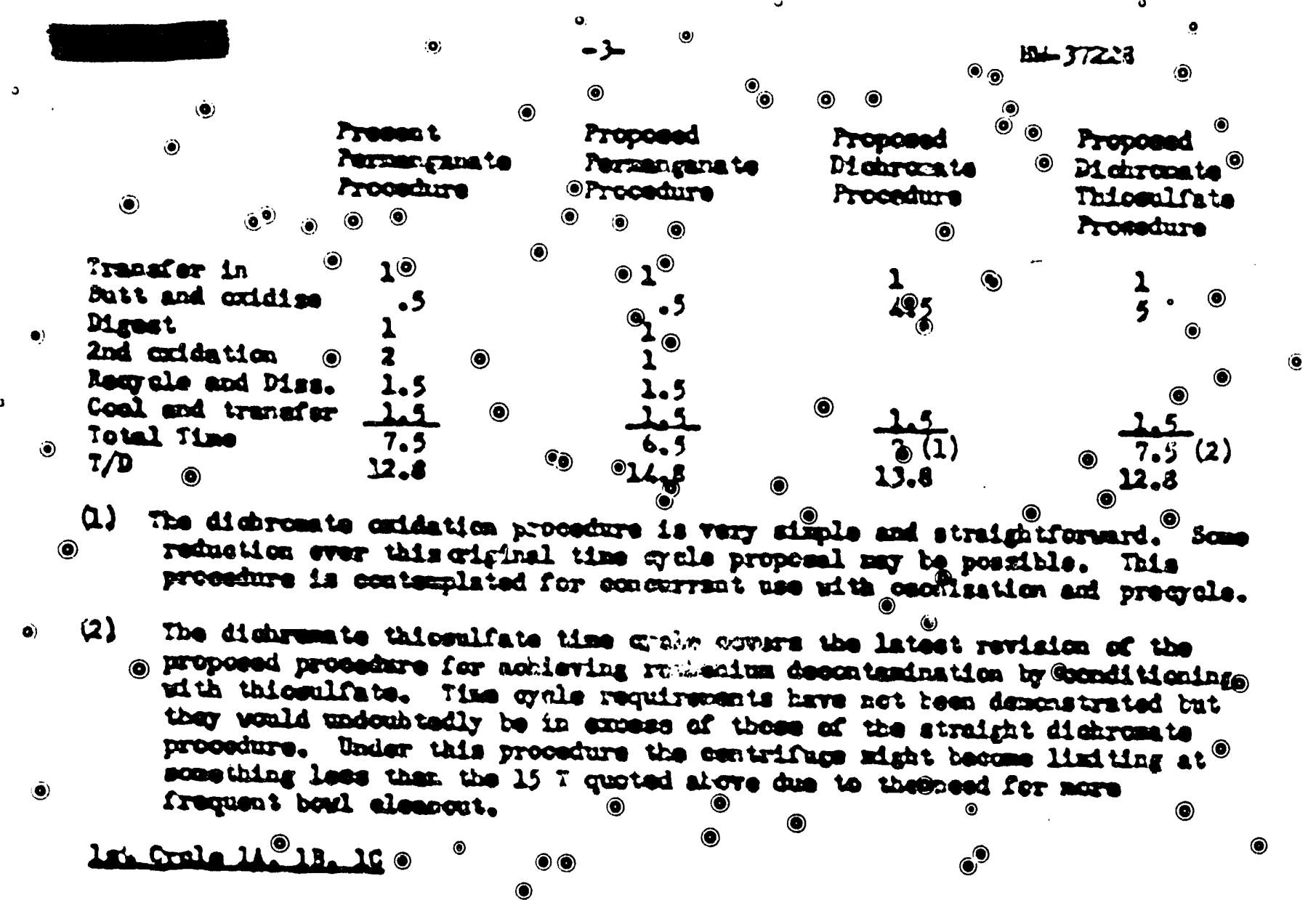

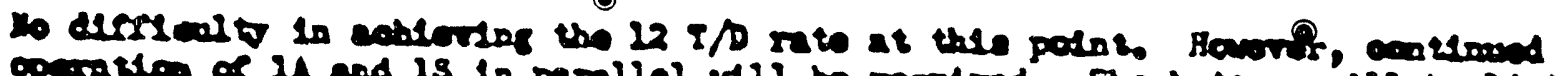

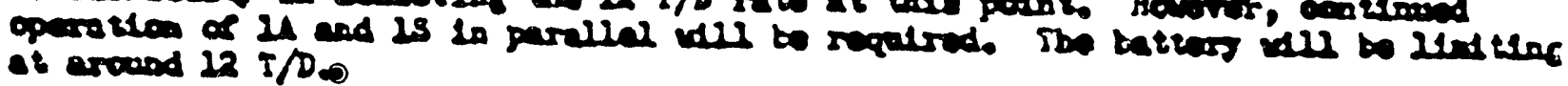

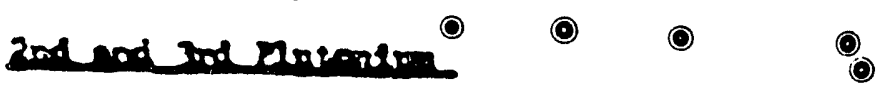

○

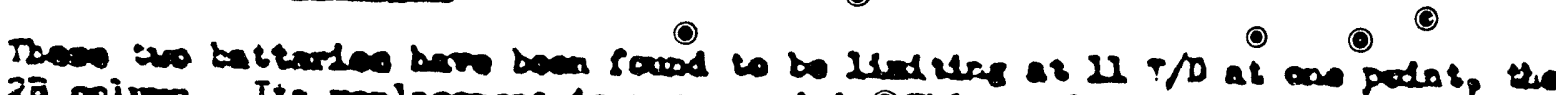

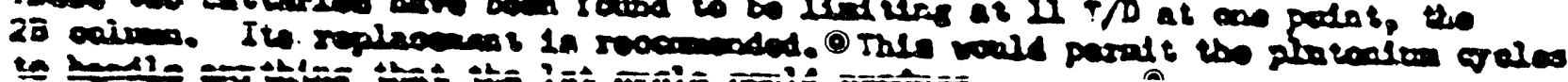

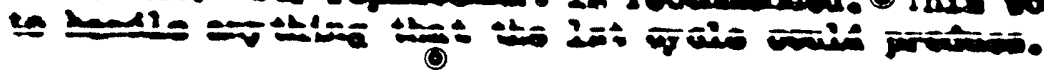

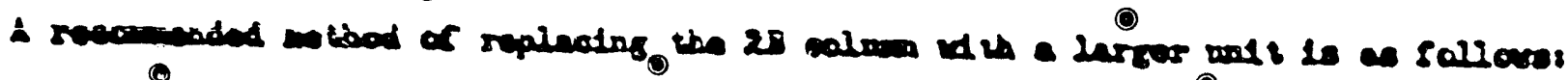

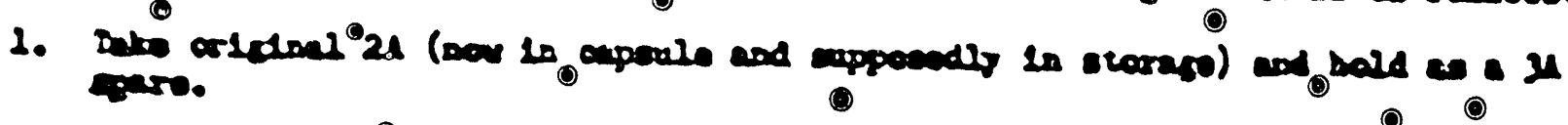

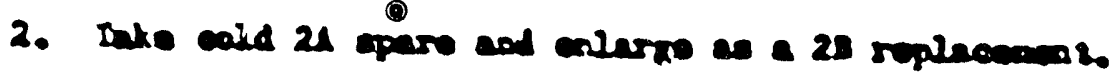

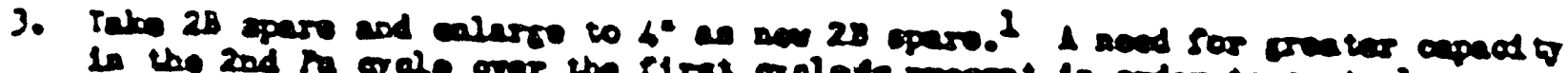

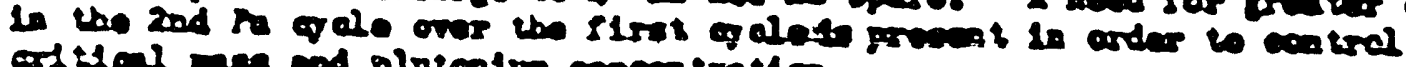

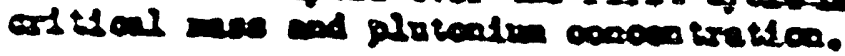

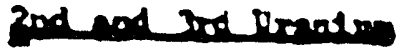

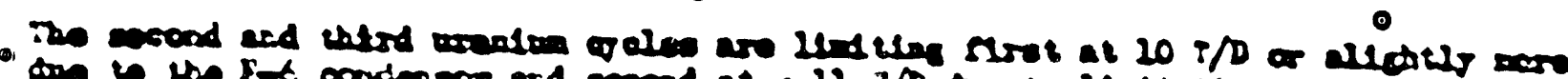

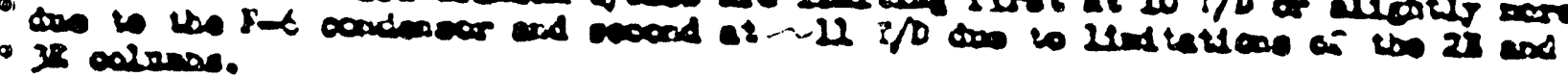

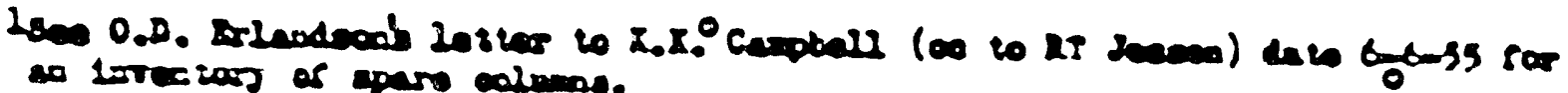
ex letecios or apare calomine. 


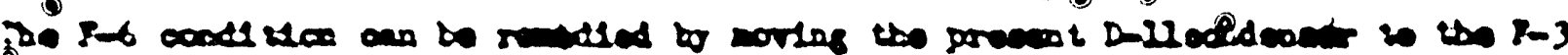

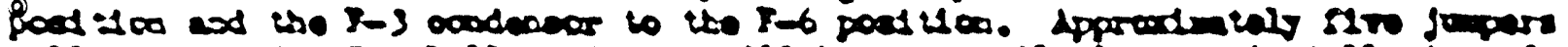

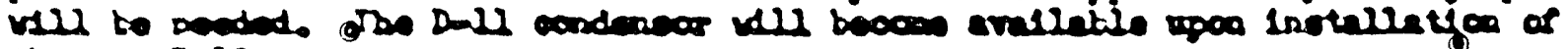
the $=0.12$ por.

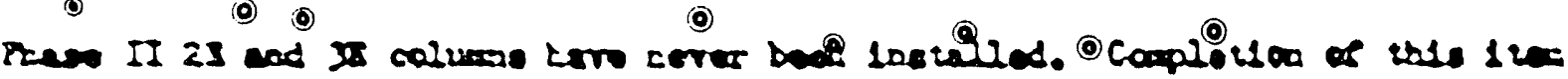

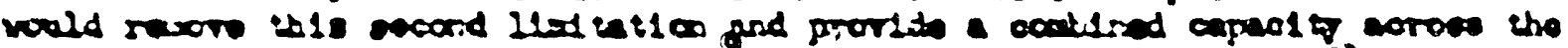

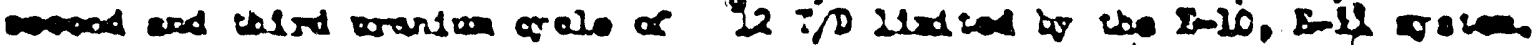

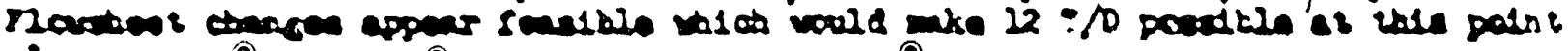
200. (i) 00

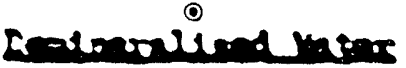

(อ) (-)

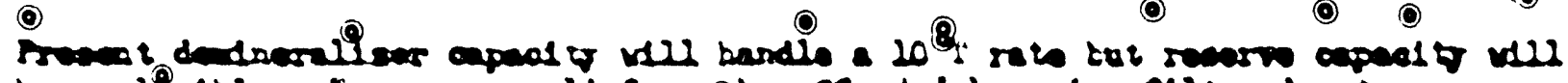

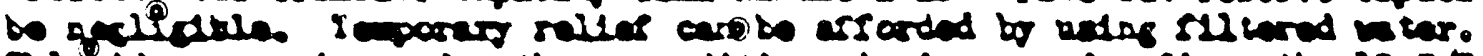

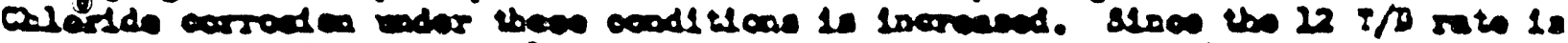

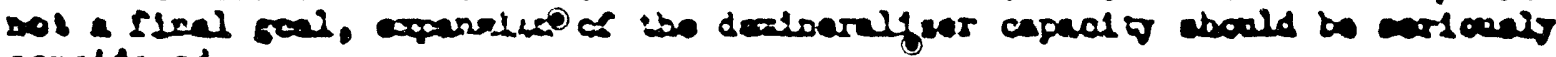
ond

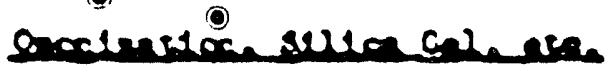

$(0)$

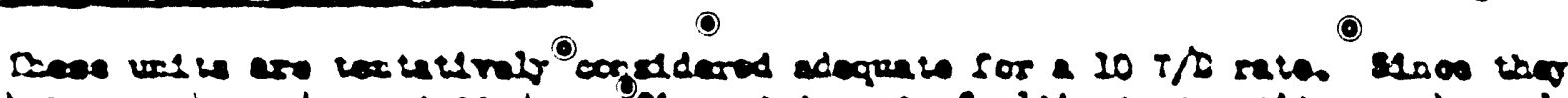
QD
()) Q

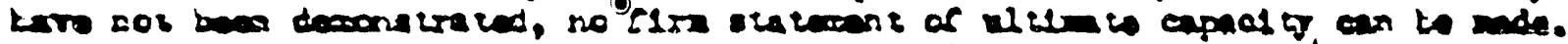

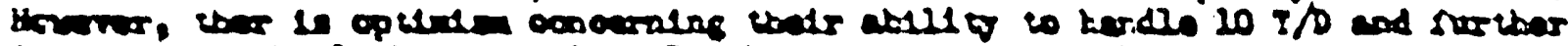

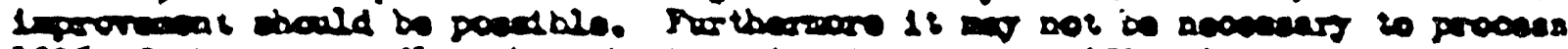

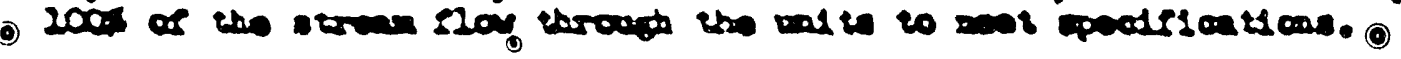
Herestere
(
(2) 9
0 (c)
(c)

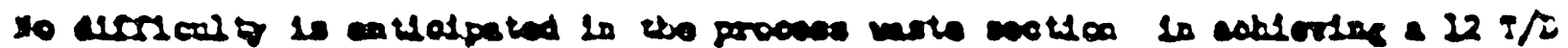

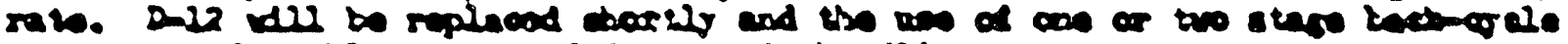

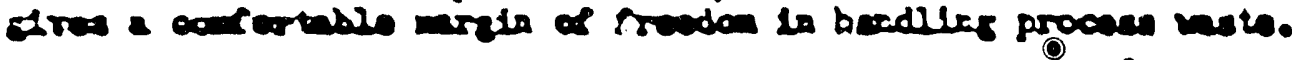

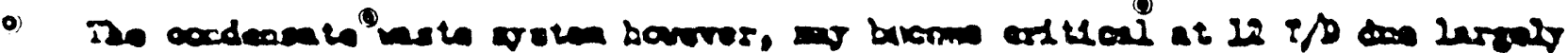

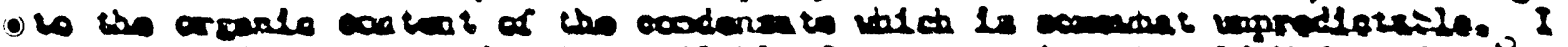

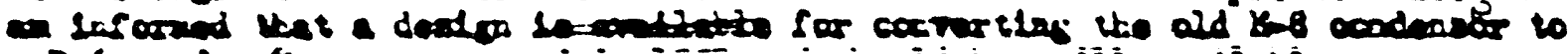
()

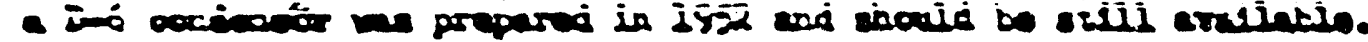

\section{comosin seret?}

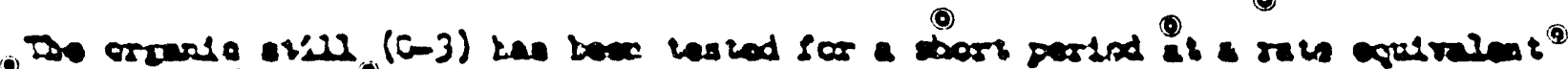

(c)

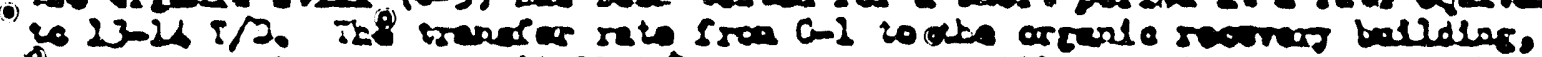

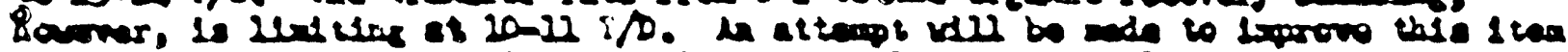

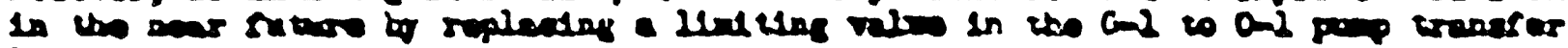
2lon.

()

()

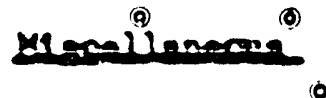

8

๑

Q.

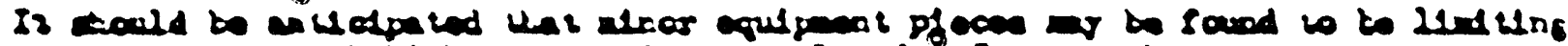

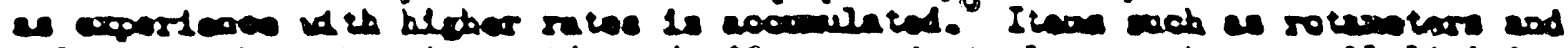

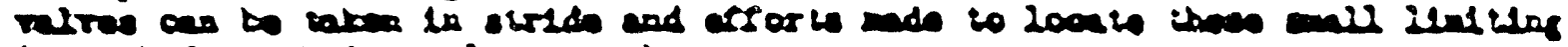

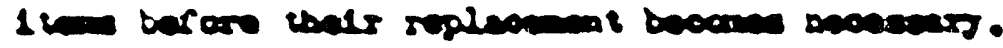

(๑)

$0^{\circ}$
(๑)

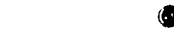

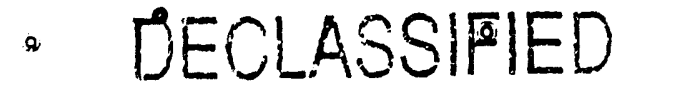


0

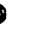

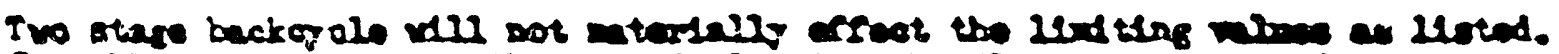

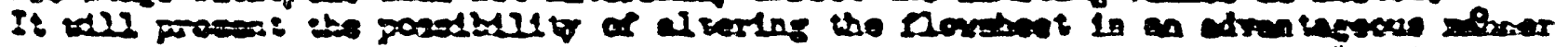

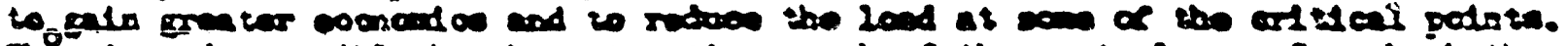

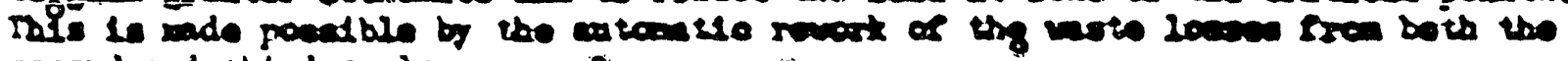
soocond and ustrd wales.

c.

o)

-)

(c)

()

()

\section{C.sien}

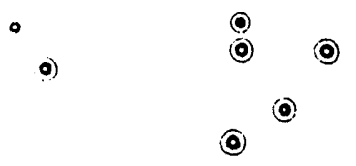

())

(๑)

(2)

$=0$

()

(

(1)

(อ)

(อ)

(9) 0 (2)

- 0 (

())

-) 0

0

()

() ๑

()

3

() 이 ()

())

()

(2)

()

(c)

(0)

()

O
8

()

\begin{abstract}
())
\end{abstract}
())

()

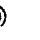

$\odot$

(i)

$\odot$

(Q)

(2)

(2)

()

()

(9)

(2) o

(Q)

(2)

(이이

O

()<smiles>[O-]</smiles>

()

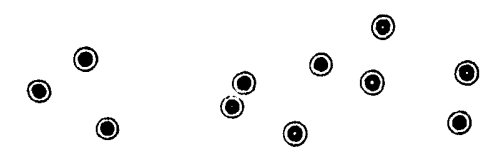

(

○ $\odot$

(๑) $\odot$

(อ)

\section{DISCLAIMER}

( )

()

○

○

o

(

O

O
0. P. Larian

Ends ind

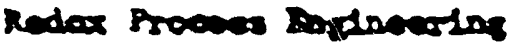

()
(9)

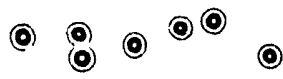

(O)
(2)
())
(0)
(ㅇ) ()

$\odot$

(๑)

@

○

○) $\odot$

$\odot$

o

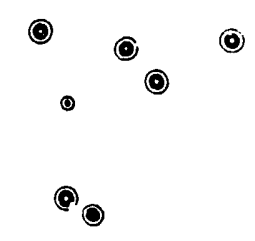

This report was prepared as an account of work sponsored by an agency of the United States Government. Neither the United States Government nor any agency thereof, nor any of their employees, makes any warranty, express or implied, or assumes any legal liability or responsibility for the accuracy, completeness, or usefulness of any information, apparatus, product, or process disclosed, or represents that its use would not infringe privately owned rights. Reference herein to any specific commercial product, process, or service by trade name, trademark, manufacturer, or otherwise does not necessarily constitute or imply its endorsement, recommendation, or favoring by the United States Government or any agency thereof. The views and opinions of authors expressed herein do not necessarily state or reflect those of the United States Government or any agency thereof.

()

(2)

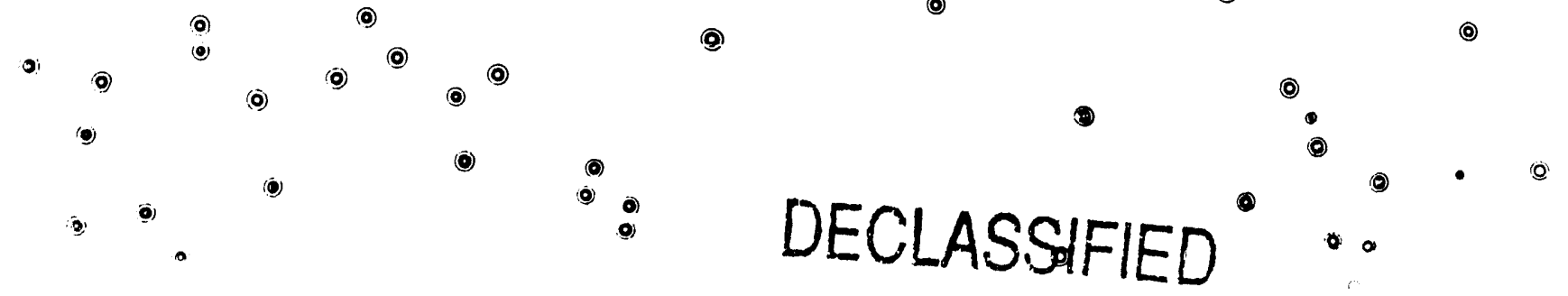

()

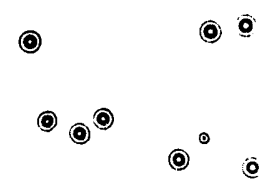

() 


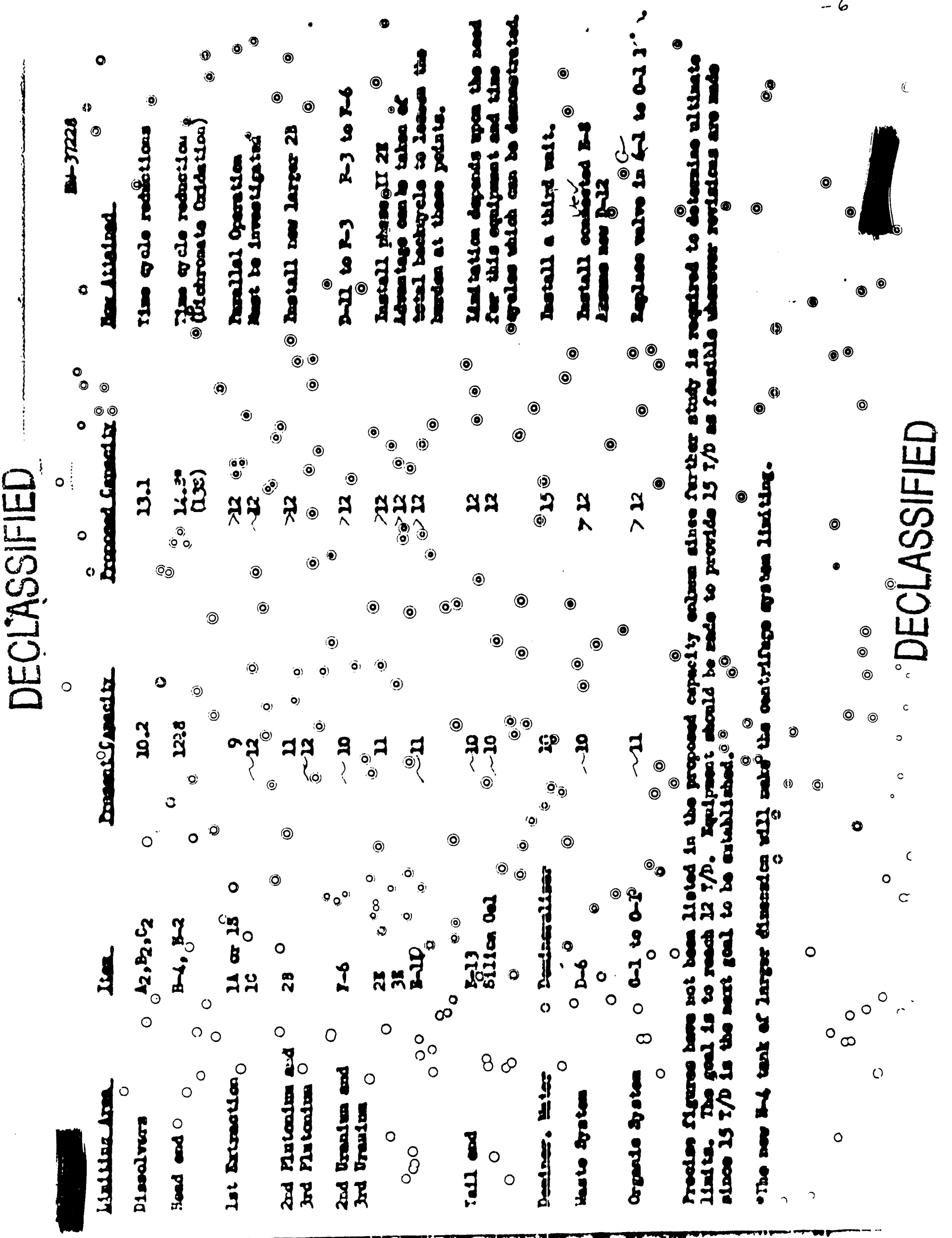



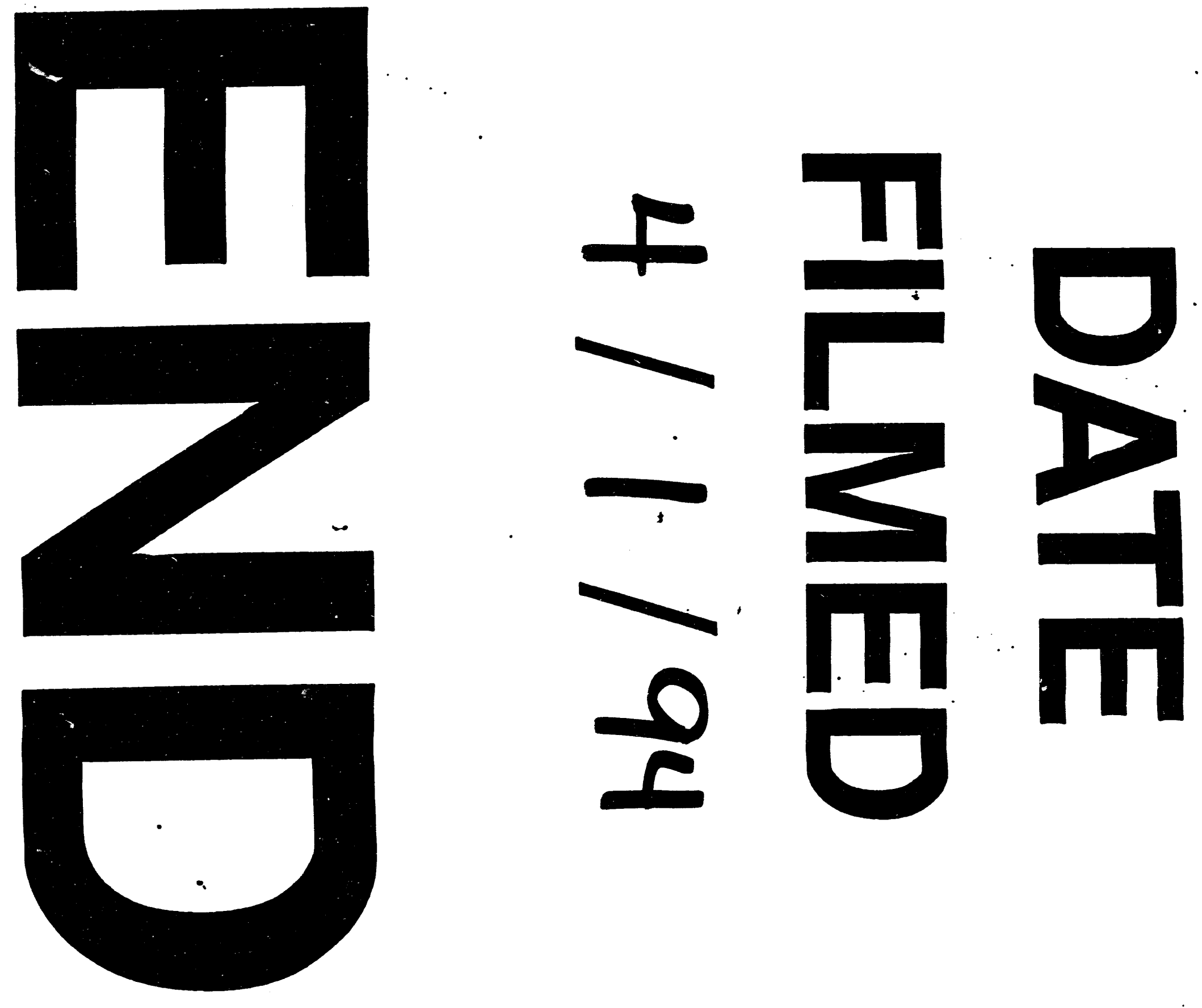
